\title{
ASSISTÊNCIA DE ENFERMAGEM À MULHER QUE PROVOCOU ABORTO DISCUTIDA POR ENFERMEIRAS EM BUSCA DE UMA ASSISTÊNCIA HUMANIZADA
}

\author{
A DISCUSSION ON THE NURSING ASSISTANCE PROVIDED TO WOMEN WHO PROVOKED \\ ABORTION LOOKING FORWARD TO NA HUMANIZED ASSISTANCE
}

\author{
LA ASISTENCIA DE ENFERMERÍA A LA MUJER QUE PROVOCÓ ABORTO ES DISCUTIDA POR \\ LAS ENFERMERAS PARA BUSCAR UNA ASISTENCIA HUMANIZADA
}

Autora: Jussara Mendes Lipinski Orientadoras: Valéria Lerch Lunardi e Adriana Dora da Fonseca

O presente trabalho decorre da percepção do modo discriminatório e possivelmente descomprometido, pelo qual as mulheres que internam por aborto provocado são atendidas pela equipe de enfermagem de uma Unidade de Internação Obstétrica (UIO). A partir de Paulo Freire, utilizou-se, como caminho metodológico, um círculo de Reflexão-Ação com enfermeiras que atuam nesta unidade; tendo emergido das discussões do grupo a seguinte temática: 1 . Visão das enfermeiras do aborto como um ato banal; 2 . Sua percepção da dificuldade em assistir as mulheres que provocam aborto; 3 . A cliente como objeto ou sujeito de nossas ações; 4 . Refletindo acerca de mudanças na assistência à mulher que provoca aborto - sentimentos das enfermeiras. O trabalho iniciado possibilitou a reflexão da equipe de enfermagem como um todo sobre a assistência prestada às mulheres que internam por aborto provocado, além da tentativa de implementação de um modelo de processo de enfermagem, adaptado a partir de Travelbee.

\section{HUMANIZAÇÃO EM TERAPIA INTENSIVA: UM ESTUDO COMPREENSIVO COM OS PROFISSIONAIS QUE ASSISTEM CRIANÇAS}

\author{
HUMANIZATION IN THE INTENSIVE THERAPY: A STUDY WITH PROFESSIONALS WHO ASSIST \\ CHILDREN
}

\section{HUMANIZACIÓN EN TERAPIA INTENSIVA: UN ESTUDIO COMPRENSIVO CON LOS PROFESIONALES QUE ASISTEN A LOS NIÑOS}

Autora: Poliana Renata Cardoso Orientadora: Cláudia Maria de Mattos Penna

Trata-se de um estudo qualitativo de inspiração fenomenológica que buscou compreender o significado da assistência humanizada à criança internada em terapia intensiva sob a ótica dos profissionais de saúde. Realizou-se entrevista com 9 profissionais, entre médicos, enfermeiros e auxiliares de enfermagem, fisioterapeutas, que atuam em uma Unidade de Terapia Intensiva em um hospital de Belo Horizonte, a partir da questão norteadora: qual o significado da humanização na assistência para você? Após leituras sistemáticas dos relatos surgiram unidades sistemáticas que revelaram questões relacionadas com o cuidado; a morte; o ambiente e o espaço físico que estão reunidos nas seguintes categorias: 1) Cuidado: a expressão do humanizar - subdividido em "e o cliente é um ser humano..." e "cuidar verbo feminino"; 2) Profissionais da saúde: os insensiveis sensiveis; 3 ) O cuidado e a técnica no espaço humanizado - subdividido em "a necessidade de saber executar a técnica" e "o ambiente como suporte". As reflexões desvelaram que apesar desses profissionais serem considerados insensiveis e muitas vezes utilizarem técnicas sofisticadas, há um resgate da humanização no dia a dia da assistência à clientela ali internada.

\footnotetext{
${ }^{1}$ Cópia das teses/dissertações solicitar informações pelo e-mail cepen@abennacional.org.br.
} 